\title{
Memory for music
}

\author{
DEAN DELIS, JOHN FLEER, AND NANCY H. KERR \\ University of Wyoming, Laramie, Wyoming 82071
}

\begin{abstract}
Subjects created imaginal interpretations of classical music passages in accordance with themes which were either concrete and comprehensible or abstract and difficult to comprehend. Recognition memory for the musical passages was found to be superior in the former condition. The results support the hypothesis that meaningful interpretation of stimulus material is a major determinant of memory accuracy. The implications of the results for comparisons of music and language are also discussed.
\end{abstract}

The present experiment is concerned with the effect of people's meaningful interpretations of musical passages on their subsequent memory for them. Meyer (1967) has distinguished between two types of meaning in music, calling the melodic properties of a passage the "embodied meaning" and the images and ideas that a passage may evoke the "designative meaning." Meyer has noted that the structural characteristics of "embodied meaning" of a musical passage affect an individual's memory for the music, and recent research supports his observation (Dowling, 1973; Dowling \& Fujitani, 1971; Dowling \& Hollombe, 1977; White, 1960). Thus, just as one tends to remember familiar and well-organized visual (Goldstein \& Chance, 1971) and linguistic (Miller \& Selfridge, 1950) patterns, one also has better memory for musical passages which have coherent "embodied meaning." The current study was designed to determine whether the "designative meaning" of a musical passage also affects memory for the music itself.

The possibility that designative meaning may affect memory for music follows directly from recent research which indicates that the meaningful interpretation of a stimulus material is an important determinant of memory accuracy. For example, both Bransford and Johnson (1972) and Bransford and McCarrell (1974) tested recall for linguistic materials and found that memory for sentences was enhanced when the subject had been provided with a meaningful context for the sentences. Wiseman and Neisser (1974) used ambiguous pictures as stimuli in a recognition experiment and found that subjects had better memory for those pictures perceived as faces than for those perceived as meaningless patterns of black and white. Bower, Karlin, and Dueck (1975) found that recall of potentially meaningless pictures

We would like to thank Sandy Wiseman and David Foulkes for their helpful comments on an earlier draft, and Hugh McGinley for his assistance with statistical analysis. Requests for reprints should be addressed to Dean Delis, Psychology Department, University of Wyoming, Laramie, Wyoming 82071. (droodles) was improved when subjects were given a verbal interpretation which gave the pictures a meaning. All of these studies share the same general experimental procedure: (1) subjects are presented with stimulus materials which are difficult to "understand"; (2) a record is kept of which of the stimulus materials are meaningfully interpreted by the subjects; and (3) the subjects are given a memory test for the material. The studies all have shown that memory for a stimulus is superior when the subjects "understand its underlying meaning, " supporting the hypothesis that memory performance is not a function of the surface characteristics of the stimulus alone (the medium), but that the subjects' understanding of the meaning of the stimulus (the message) is an important determinant of memory for the material.

Since music can be thought of as having both a surface string of notes and an underlying designative meaning, musical stimuli can be used in an experiment on memory analogous to the experiments described above. However, there is one important difference between the symbolic properties of music and those of language and pictures. Unlike words and pictures, musical notes do not act as socially agreed upon referents to objects and events in the physical world, and thus there is no guarantee that one person's designative interpretation of a musical passage will be similar to another's. Early research (Downey, 1897) demonstrated that, although emotional reactions to music may be similar across individuals, the images, thoughts, and ideas which listeners associate to a particular passage are generally very different. Thus, while in previous research employing linguistic and visual stimuli the material had an inherent deep meaning which could be "discovered" by the subjects, in an experiment employing musical stimuli the subjects' task would be to create their own designative interpretations. This suggests the hypothesis that subjects can improve their memory for musical passages by creating richer, more elaborate designative interpretations of the passages. 
In order to test the hypothesis, the following experimental procedure was developed. Subjects were asked to make designative interpretations of musical passages by constructing visual images while listening to them. Imagery was chosen as the vehicle for making designative interpretations because it has been found that music readily lends itself to the evocation of visual images (Seashore, 1967), and because visual imaging has been found to be a powerful strategy in general for enhancing memory for linguistic material (Paivio, 1969). The subjects' designative interpretations of the musical passages were manipulated by presenting the same musical passages with several different titles, half of the titles referring to objects, scenes, or events which had been rated as highly "concrete" and "comprehensible," the other half, as "abstract" and "difficult to comprehend." By instructing subjects to try to imagine, as they listened to the music, those things to which the title of a particular passage referred, it was possible to test whether the easy-to-comprehend titles would encourage richer designative interpretations of the music than the difficult-to-comprehend titles, and if so, whether subsequent memory for the music would be enhanced.

\section{METHOD}

\begin{abstract}
Subjects
The subjects were 36 students ( 9 females, 27 males) from introductory psychology courses at the University of Wyoming, who volunteered for the experiment to receive extra class credit. They were run in individual sessions.
\end{abstract}

\section{Procedure and Materials}

The subjects were individually presented with six 1-min passages of classical music. The passages were taken from a selection of 2019 th and 20th century symphonic pieces, all of which were full orchestral works. In order to minimia the possibility that some subjects might be familiar with particular works of music, thus giving them an advantage on the memory test, the 20 symphonic pieces were played to an independent group of psychology undergraduates ( $n=32$ ) who were asked to rate each passage on a scale ranging from "1" (very familiar) to " 7 " (never heard before). The six passages which received the lowest "familiarity" ratings were chosen for the experiment (Bartok's Divertimento for Orchestra, second movement; Berlioz's Symphonie Fantastique, first movement; Mahler's Symphony No. 2, first movement; Prokofiev's Love for Three Oranges, part five; Nielson's The Inextinguishables, first movement; and Debussy's Prelude to the Afternoon of a Faun, first movement. The mean "familiarity" rating was 5.49 ).

At the start of the experiment; a sheet listing six titles was placed before the subject, who was told that the titles were the composers' thematic interpretations of the music. Three of the titles had been rated independently by a group of psychology undergraduates $(\tilde{i}=33)$ as highly councrete allù easy io comprehend, and three had been rated as abstract and difficult to comprehend (concrete titles: Ocean Voyage, Peasants in the Field, and Winter Forest; abstract titles: Refuge in Truth, Philosophical Questions, and Rebirth of Justice). The six titles were ordered randomly on six different sheets with the constraint that each title be paired equally with all six passages of music; the sheets were assigned randomly to the 36 subjects with the constraint that each title sheet be presented to six subjects. In this way, the same passage of music was paired equally with all six titles, with six subjects imaging to each music-title combination.

Before listening to a passage, the subjects were instructed to: read the title of that passage; listen to the passage and mentally visualize those things to which the title referred that possibly could be related to the sounds of the music; after hearing each passage, describe their images into a tape recorder; and rate their images for each passage in terms of how vivid they were, on the average. (Sheehan's 1967 adaptation of Bett's vividness of imagery scale was used.) The subjects were asked to describe their images of the passages as a check to be sure that they had understood the instructions. The vividness of imagery scale was used as the measure of the richness of the subjects' designative interpretations of the passages.

After the images to all six passages were described and rated, subjects were given an incidental recognition test, which consisted of 245 -sec passages. Twelve of the 5 -sec passages were taken from the test passages used in the imaging phase of the experiment (two 5 -sec passages from each 1 -min passage), and 12 were taken from other classical music sources (from symphonic pieces which also received low familiarity ratings: Sibelius' Symphony No. 1 , first movement; Beethoven's Symphony No. 3, second movement; Stravinsky's Firebird, first movement; Lalo's Symphonie Espagnole, fourth movement; Thompson's Louisiana Suite, pastoral; Rachmaninoff's Symphony No. 3, first movement. The mean "familiarity" rating of these passages was 5.04). The subjects were told to write "yes" if they recognized the 5-sec passage as taken from the six passages they had just heard, and "no" if they did not recognize the test passage. In addition, they were asked to rate their confidence in all of their answers using a 5-point scale, with " 1 " indicating very little confidence and " 5 " indicating high confidence. The unexpected recognition test was used to avoid the possibility that subjects might use strategies of remembering other than imaginal elaboration.

\section{Apparatus}

The six 1 -min and 245 -sec passages were played from a Teac tape recorder, Model A-2340. Subjects listened to the passages through Telex headphones, Model ST-20.

\section{RESULTS}

\section{Vividness Ratings}

Vividness ratings ranged from "1" (very vivid) to "7" (no image). A 6 (passages) by 2 (concrete vs. abstract title) within-subjects factorial design was used. Table 1 shows the mean vividness ratings for the concrete and abstract title conditions. Differences assessed using a within-subjects analysis of variance showed that images were rated significantly more vivid when associated with the passages that had been given concrete titles than when associated with those

Table 1

Mean Vividness Ratings and Recognition Scores for Musical Passages When Assigned Easy- or Difficult-to-Comprehend Titles

\begin{tabular}{lcc} 
Titles & $\begin{array}{c}\text { Vividness } \\
\text { Ratings* }\end{array}$ & $\begin{array}{c}\text { Recognition } \\
\text { Scores** }\end{array}$ \\
\hline Easy to Comprehend & 2.92 & 6.77 \\
Difficult to Comprehend & 4.68 & 5.79 \\
\hline
\end{tabular}

* Lower numbers indicate more vivid imagery.

**Higher numbers indicate better recognition memory. 
given abstract titles $[F(1,35)=13.198, p<.005]$; there were no other significant effects. This finding supports the hypothesis that concrete titles lead to richer, more elaborate, designative interpretations of the music.

\section{Recognition Scores}

Only the recognition test responses associated with the 125 -sec passages taken from the original passages were analyzed for effect of title on passage recognition, since the 12 "new" distractor items were paired with neither a concrete nor an abstract title. A "yes" response to one of the original passages was therefore a hit, and a "no" response was a miss. Each recognition response was combined with its accompanying confidence rating (1-5) and assigned a numerical value from 1 to $10,1-5$ corresponding to incorrect responses, 6-10 to correct responses, and the deviation from 5 or 6 to the degree of confidence. Thus, a "yes" response with a confidence rating of 5 was assigned a value of " 10 ," the most correct possible score, since the confidence rating indicates that the subject claimed not to be guessing; a "no" response with a confidence rating of 5 was assigned a " 1 ," the most incorrect possible score, since the confidence rating indicates that the subject was not unsure of the response. A "yes" response with a confidence rating of 4 was assigned a "9"; a "no" response with a confidence of 4 was assigned a " 2 "; etc. Thus, the closer the confidence rating of a response approached 1 , the more the subject was objectively/subjectively wrong.

The dependent measure is patterned after the method used in previous studies (Bransford, Barclay, \& Franks, 1972; Bransford \& Franks, 1971) to assess recognition memory in a completely within-subjects design. We employed a scale from 1 to 10 , instead of a scale from -5 to +5 as had been used previously, to avoid artificial inflation of the difference due to the gap at the zero value between positive and negative scores.

Since the recognition test contained two $5-\mathrm{sec}$ passages from each of the six original passages, each subject gave two responses in each treatment condition. The design was thus a 6 (passages) by 2 (concrete vs. abstract title) by 2 (recognition responses) within-subjects factorial. Table 1 shows the mean recognition scores for the concrete and abstract title conditions. A within-subjects, repeated measures analysis of variance revealed significantly better recognition when passages were given concrete rather than abstract titles $[\mathrm{F}(1,35)=11.87, \mathrm{p}<.005]$. There was also a significant passage effeci $[F(5,35)=6.02$, $\mathrm{p}<.01$ ]; however, there were no significant interaction effects, indicating that recognition scores were not inflated due to specific title-passage combinations. These results support the hypothesis that inter- preting a musical passage in accordance with easy-tocomprehend themes improves memory for the passage.

Since the observed effects of passage title are based on entirely within-subjects comparisons, there is no reason to believe that subjects' overall guessing strategies affected the two kinds of material differentially. Nevertheless, the possibility that response biases existed was tested by analyzing the responses to the distractor items using a system similar to that used for the experimental items. A "no" response to a distractor item was a correct rejection, and a "yes" response was a false alarm. A "no" response with a confidence rating of 5 was assigned a recognition score of " 10 ," the most correct possible rejection of a distractor item; a "yes" response with a confidence rating of 5 was assigned a "1," the most incorrect possible false alarm. The recognition scores for distractor items thus ranged from 1 to $10,1-5$ corresponding to false alarms, 6-10 to correct rejections, and the deviation from 5 or 6 to the degree of confidence. The mean recognition score for distractor items was "6.1." That this value is greater than " 5 ", indicates that the subjects did not have a general response bias to report "yes."

\section{DISCUSSION}

As Bower et al. (1975) have noted, experiments which show the importance of "understanding" the meaning of linguistic and pictorial material for memory accuracy are "intuitively obvious," their significance being to demonstrate weaknesses in theoretical orientations which address only the surface characteristics of the stimuli to be remembered. The present experiment addresses a question, however, whose answer is less obvious. Since the relationship between the surface string of notes and designative meaning in music is arbitrary, it is not readily apparent that "real world" interpretations would affect memory for music. Intuitively, it would seem that only the structural properties-the "embodied" meaning-would need to be addressed. However, the present study indicates that interpreting patterns of notes into comprehensible themes serves to impart organization upon the notes in much the same way that discovering "faces" in patterns of black and white (Wiseman \& Neisser, 1974) serves to organize the patterns for more fluent assimilation into existing cognitive schemata. Presumably, subjects who are able to provide a coherent perceptual interpretation of a musical passage on its initial presentation are reminded of that interpretation on subsequent exposure and are able to report recognition of the music.

The present study also has implications for researchers and theorists interested in drawing analogies between language and music. Previous research has 
suggested that encoding strategies for music and language may be similar, but the empirical basis has been limited to evidence that stimulus characteristics, such as rhythmic grouping and rate of presentation, are systematically related to subjects' responses to both musical and verbal stimuli (Dowling, 1973). The current study extends previous findings by demonstrating that the processing strategies and skills that subjects use in a given experimental task may affect encoding of and memory for music as well as for verbal materials. Thus, just as a subject's memory for a verbal passage may be affected by the referential interpretation assigned by the experimenter or supplied by the subject (Bransford \& McCarrell, 1974), memory for a musical passage may be similarly affected. The finding also provides an empirical base for the distinction between "embodied" and "designative" meaning in music by showing a significant and independent effect of "designative meaning" as a determinant of memory.

\section{REFERENCES}

Bower, G. H., Karlin, M. B., \& Dueck, A. Comprehension and memory for pictures. Memory \& Cognition, 1975, 3, 216-220.

Bransford, J. D., Barclay, J. R., \& Franks, J. J. Sentence memory: A constructive versus interpretive approach. Cognitive Psychology, 1972, 3, 193-209.

Bransford, J. D., \& Franks, J. J. The abstraction of linguistic ideas. Cognitive Psychology, 1971, 2, 331-350.

Bransford, J. D., \& Johnson, M. K. Contextual prerequisites for understanding: Some investigations of comprehension and recall. Journal of Verbal Learning and Verbal Behavior, $1972,11,717-726$.
Bransford, J. D., \& MCCARRELl, N. S. A sketch of a cognitive approach to comprehension: Some thoughts about understanding what it means to comprehend. In W. B. Weimer \& D. S. Palermo (Eds.), Cognition and the symbolic processes. Hillsdale, N.J: Erlbaum, 1974.

Dowling, W. J. Rhythmic groups and subjective chunks in memory for melody. Perception \& Psychophysics, 1973, 14. $37-40$.

Dowling, W. J., \& Fujitani, D. S. Contour, interval, and pitch recognition in memory for melodies. Journal of the Acoustical Society of America, 1971, 49, 524-531.

Dowling, W. J., \& Hollombe, A. W. The perception of melodies distorted by splitting into several octaves: Effects of increasing proximity and melodic contour. Perception \& Psychophysics, 1977, 21, 60-64.

Downey, J. E. A musical experiment. American Journal of Psychology, 1897, 9, 63-69.

Goldstein, A. G., \& Chance, J. E. Recognition of complex visual stimuli. Perception \& Psychophysics, 1971, 9, 237-241.

MeYer, L. B. Music, the arts, and ideas. Chicago: University of Chicago Press, 1967.

Miller, G. A., \& Selfridge, J. A. Verbal context and the recall of meaningful material. American Journal of Psychology, 1950, 63, 176-187.

PAIvio, A. Mental imagery in associative learning and memory. Psychological Review, 1969, 76, 241-263.

Seashore, C. E. Psychology of music. New York: Dover, 1967.

Sheehan, P. W. A shortened form of Betts' questionnaire upon mental imagery. Journal of Clinical Psychology, 1967, 23, 386-389.

WhITE, B. Recognition of distorted melodies. American Journal of Psychology, 1960, 73, 100-107.

Wiseman, S., \& Neisser, U. Perceptual organization as a determinant of visual recognition memory. American Journal of Psychology, 1974, 4. 675-681.

(Received for publication August 16, 1977; revision accepted January 9,1978 .) 